\title{
Interaction between Smoking and the STAB2 Gene in the Severity of Rheumatoid Arthritis
}

\author{
Jin-Young Min ${ }^{1}$, Kyoung-bok Min², Joohon Sung ${ }^{3}$ \\ and Sung-II $\mathrm{Cho}^{3 *}$ \\ ${ }^{1}$ Institute of Health \& Environment, Seoul National \\ University, Seoul 110-799, Korea, ${ }^{2}$ Department of Pre- \\ ventive Medicine, Ajou University School of Medicine, \\ Suwon 443-749, Korea, ${ }^{3}$ Department of Epidemiology, \\ School of Public Health, Seoul National University, \\ Seoul 110-799, Korea
}

\begin{abstract}
Rheumatoid arthritis (RA) is a chronic autoimmune disorder that is characterized by inflammation of the synovial tissue and deterioration of the joint and bone. A recent study reported a potential gene-environment interaction between HLA-DR and smoking. The present study investigated whether a specific gene was related to the association between smoking and the severity of RA (rheumatoid factor levels $>20 \mathrm{IU} / \mathrm{ml}$ ). We used the resources of the NARAC family collection of GAW 15 databases, and 1139 subjects with RF $>20 \mathrm{IU} / \mathrm{ml}$ were included in the current analysis. The linkage panel contained 5858 SNP markers, and 5744 SNPs passed quality control criteria. Linear regression analyses, using PLINK software and generalized estimating equation regression models, were used to test for associations between the SNPs and the severity of RA according to smoking groups. Two major findings were established. First, the severity of RA in smokers was associated with rs703618 $\left(p=6 \times 10^{-5}\right)$, which lies in the intronic region of the stabilin 2 (STAB2) gene on chromosome 12 . Second, there were significant differences in the levels of RF between 'ever smokers' and 'never smokers' according to the rs703618 genotype (G/G, A/G, A/A). We investigated whether a specific gene acts as a mediator between smoking and the severity of RA and found that the STAB2 gene could affect this relationship. Our finding indicates that smoking may mediate RA severity by affecting the expression level of a specific gene.
\end{abstract}

Keywords: gene-environment interaction, hyaluronic acid, rheumatoid arthritis, smoking

*Corresponding author: E-mail scho@snu.ac.kr

Tel +82-2-740-8868, Fax +82-2-740-8893

Accepted 20 January 2009

\section{Introduction}

Rheumatoid arthritis (RA), which is a chronic autoimmune disorder that is characterized by inflammation of the synovial tissue and deterioration of the joint and bone, causes severe disability and increases mortality (Lee and Weinblatt, 2001).

There is substantial evidence that genetic factors play crucial roles in the occurrence of RA. The genes for MHC class II, particularly the HLA-linked genes, show consistent and strong associations with the onset of RA (Gregersen et al., 1987; de Vries et al., 2002; Turesson and Matteson, 2006). In addition, several environmental factors are implicated in the development or progression of RA (Klareskog et al., 2006). Of these factors, smoking is suspected to be an important contributor to the occurrence and severity of RA (Harrison, 2002; Alamanos and Drosos, 2005). Silman et al. (1996) investigated smoking-discordant twin pairs with RA and found that smoking was associated with susceptibility to RA. Smokers show an increased incidence of RA and elevated levels of rheumatoid factor (RF) (Saag et al., 1997; Masdottir et al., 2000; Wolfe, 2000), which is an indicator of RA severity (Cabral et al., 2005).

Considering that the occurrence of RA reflects the interaction between genetic and environmental factors, an approach to estimating such interactions would be useful in the detection of RA susceptibility genes. A recent study reported a potential gene-environment interaction between the shared epitope of HLA-DR and smoking. In RF-seropositive RA, HLA-DRB1 genotypes are associated with smoking, which means that a gene that is defined as a risk factor for RA is strongly affected by this environmental factor (Padyukov et al., 2004).

We hypothesized that smoking has a significant effect on the elevation of RA and that this relationship is mediated by the function of a specific gene. This purpose of this study was to investigate the gene-environment interaction between smoking and the severity of RA.

\section{Methods}

\section{Subjects}

We used the resources of the $15^{\text {th }}$ Genetic Analysis Workshop (GAW 15) database and the North American Rheumatoid Arthritis Consortium (NARAC) family collec- 
tion. Families were recruited from 12 NARAC centers in the USA according to following criteria: 1) at least 1 sibling had documented erosions on hand radiographs; and 2) at least 1 sibling had disease onset between the ages of 18 and 60 years (Jawaheer et al., 2001). The dataset included 823 families (92\% Caucasian, 5\% Hispanic, $2 \%$ African, $0.6 \%$ Asian, and $0.4 \%$ Native American) with 1966 affected siblings with RA.

Age, sex, smoking history, and serum RF were evaluated in the present study. Smoking histories were categorized as 'Ever smokers' or 'Never smokers' after RA onset, because RA patients are more likely to try to quit smoking, and classifying smokers based only on current smoking status may underestimate the effect of smoking. Serum samples were collected at study entry, and RF IgM was measured using a latex-enhanced nephelometric procedure. RF production has been considered the leading indicator of RA severity (Cabral et al., 2005), although there is controversy due to the detection of healthy population and the relation with age (Westwood et al., 2006). In this study, we defined the severity of RA as more than $20 \mathrm{IU} / \mathrm{ml}$ for RF levels (Aigner et al., 2007). Finally, the current analysis included 1139 subjects (689 families) with $\mathrm{RF}>20 \mathrm{IU} / \mathrm{ml}$.

Illumina performed an analysis of genome-wide SNPs with commercially available SNP panels of all of the families. Samples were genotyped using the panel of 5858 SNPs across the genome, spaced at an average distance of 0.64 cM (Illumina Inc., San Diego CA, USA, BeadArray platform and GoldenGate assay). Nearly all of these markers (98.1\%) passed quality control filters (MAF $>5 \%$, SNP call rate $>90 \%$, and HWE $p$ value $>$ 0.01 ), giving a total yield of 5744 SNPs. The results of the analysis of the NARAC Caucasian families have been published (Amos et al., 2006; Taylor et al., 2007). Detailed information on the study subjects is available at the NARAC website (http://www.naracdata.org).

Table 1. General characteristics of study subjects $(\mathrm{N}=$ 1,139)

\begin{tabular}{lcc}
\hline & Male & Female \\
\hline Age (years) & $56.54 \pm 10.87$ & $55.04 \pm 11.26$ \\
RF (IU/ml) & $362.88 \pm 510.09$ & $340.62 \pm 655.54$ \\
Smoking history & & \\
$\quad$ Never smoker & $65(23)$ & $398(46)$ \\
$\quad$ Ever smoker & $214(77)$ & $462(54)$ \\
\hline
\end{tabular}

The values were presented as mean \pm SD or $N(\%)$. Smoking histories were categorized as 'Ever smokers' or 'Never smokers' after RA onset.

\section{Statistical analysis}

The RF values were log-transformed to assure a normal distribution, and smoking habits were categorized into 'ever smoker' and 'never smoker' groups. The data analysis included 5744 genome-wide SNPs (MAF $>5 \%$, SNP call rate $>90 \%$, and HWE $p$ value $>0.01$ ) and the smoking habits of subjects with RF levels $>20 \mathrm{IU}$. For the groups that were stratified by smoking habits, family-based tests of association using PLINK software (http://pngu.mgh.harvard.edu/ purcell/plink/) were performed with all of the available SNPs, and generalized estimating equation (GEE) regression models were used to test for associations between the SNPs and the severity of RA according to smoking groups. In the model, the RF level was used as a response variable, and SNPs, age, and sex were used as explanatory variables.

To show interaction between a significant SNP and smoking status, we calculated the mean RF values for the 3 genotypes $(G / G, A / G, A / A)$ of a significant SNP and presented the least square means (95\% confidence intervals) for each allele after adjustment for age and sex (Fig. 4), using SAS software package version. 9.1 (SAS institute Inc.).

\section{Results}

Table 1 lists the general characteristics of the subjects. The mean age was 57 years in males and 55 years in females. Seventy-three percent of males responded to having a smoking history, while $52 \%$ of females had a smoking history. The mean RF value was higher in males (362.9 IU) than in females (340.6 IU). RF (>20 $\mathrm{IU} / \mathrm{ml}$ ) is log-transformed (Fig. 1).

The results from the genome-wide association analysis of RF are presented in Fig. 2, and the top 4 SNPs $\left(p<10^{-3}\right)$ are summaized in Table 2. The significant

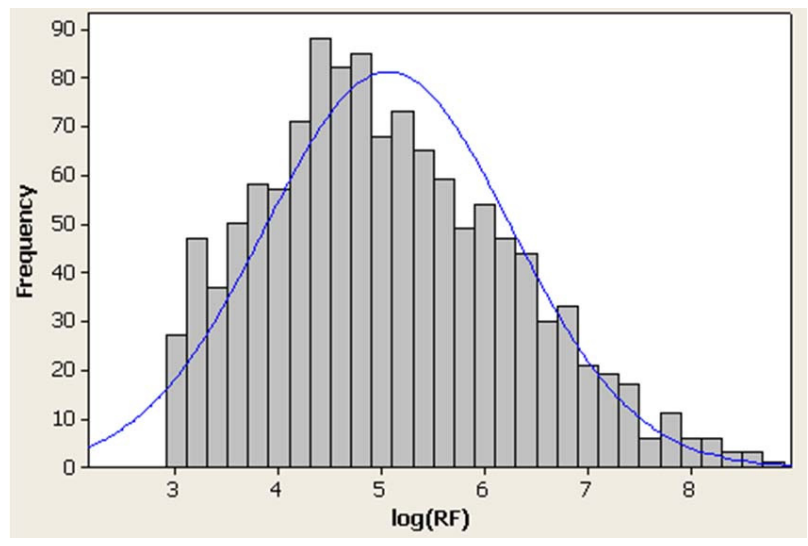

Fig. 1. Distribution of log (RF) values. 


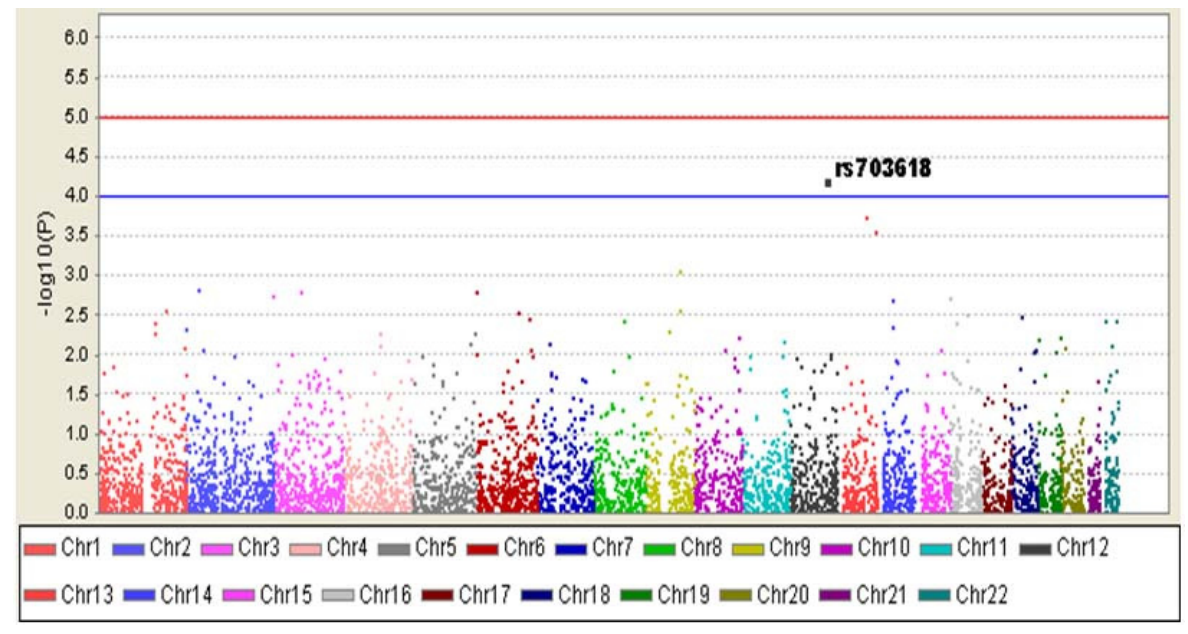

Fig. 2. Results from genome-wide association analysis of rheumatoid factor. The $y$ axis represents the $-\log 10 \mathrm{p}$ value, and the $\mathrm{x}$ axis represents each of the SNPs used in this scan.
Table 2. Summary results of association tests $\left(p<10^{-3}\right)$

\begin{tabular}{rllllll}
\hline CHR & \multicolumn{1}{c}{ SNP } & Region & Gene & Allele & MAF & p-value \\
\hline 12 & rs703618 & $12 q 23$ & STAB2 & A/G & 0.4416 & $6.23 \mathrm{E}-05$ \\
13 & rs722952 & $13 q 31$ & - & C/T & 0.4457 & 0.00019 \\
13 & rs1856277 & $13 q 33$ & MYO16 & A/G & 0.3954 & 0.000295 \\
9 & rs1338121 & $9 q 22$ & INVS & A/G & 0.4472 & 0.000907 \\
\hline
\end{tabular}

SNP in the association between smoking and RF was rs703618 $\left(p=6 \times 10^{-5}\right)$. Using the SNP database at the PubMed website, we confirmed the position and gene name of rs703618 (Table 2 and Fig. 3).

The rs703618 SNP comprises 3 genotypes (G/G, A/G, $A / A)$, and $G / G$ exists as the minor allele. 'Ever smokers' with the A/A genotype had higher RF levels than those with the G/G genotype. In contrast, the 'never smokers' showed similar RF levels for all 3 genotypes. There were significant differences in the RF levels of individuals with the A/A genotype between 'ever smokers' and 'never smokers,' while the G/G genotype was not associated with smoking status (Table 3). This trend was retained after adjustment for age and sex (Fig. 4).

\section{Discussion}

The aim of the present study was to investigate whether a specific gene was related to the association between smoking and the severity of RA (in patients with RF levels $>20 \mathrm{lU} / \mathrm{ml}$ ). Two major findings were established. First, the severity of RA in smokers was associated with $r$ 703618 $\left(p=6 \times 10^{-5}\right)$, which lies in the intronic region of the stabilin 2 (STAB2) gene on chromosome 12. Second, there were significant differences in the levels of RF between 'ever smokers' and 'never smokers' according to the rs703618 genotype (G/G, A/G, A/A). The RF levels were significantly increased in 'ever smokers'

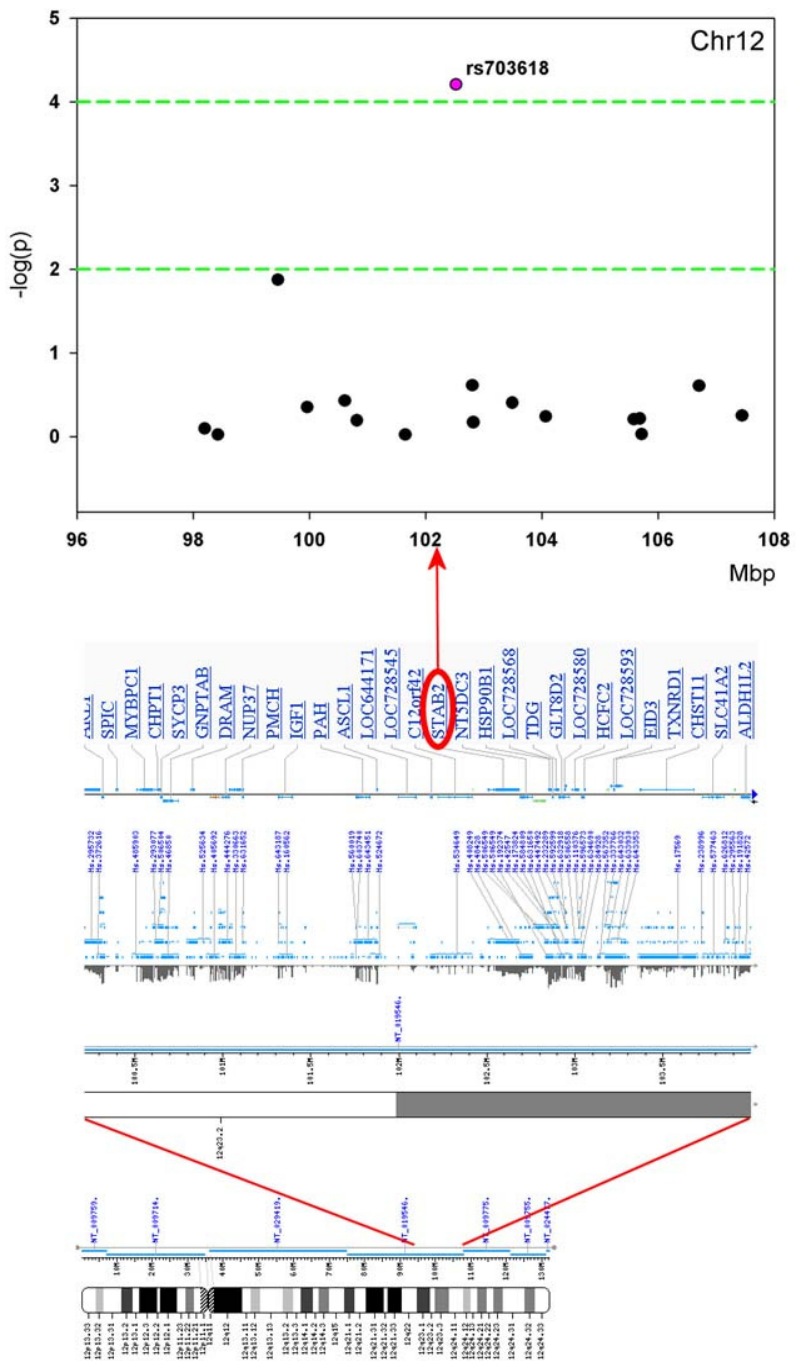

Fig. 3. Association of the STAB2 gene on chromosome 12 with severity of RA by plot of $-\log (p)$ versus chromosome position (RF>20 IU/ml, 'ever smokers'). 
Table 3. Association of RF with rs703618 genotypes by smoking history $(\mathrm{N}=1139)$

\begin{tabular}{lccc}
\hline \multirow{2}{*}{ Variable } & \multicolumn{3}{c}{ Mean trait value or N by genotype } \\
\cline { 2 - 4 } & $\mathrm{G} / \mathrm{G}$ & $\mathrm{A} / \mathrm{G}$ & $\mathrm{A} / \mathrm{A}$ \\
\hline Age (years) & $54.94 \pm 11.55$ & $55.90 \pm 11.36$ & $55.15 \pm 10.99$ \\
Sex & & & \\
$\quad$ Male & $32(11)$ & $103(37)$ & $144(52)$ \\
$\quad$ Female & $63(7)$ & $317(37)$ & $480(56)$ \\
Log (RF) & & & \\
$\quad$ Ever smokers & $4.90 \pm 1.21$ & $5.09 \pm 1.17$ & $5.28 \pm 1.20$ \\
Never smokers & $4.68 \pm 1.23$ & $4.93 \pm 1.18$ & $4.90 \pm 1.11$
\end{tabular}

The values were presented as mean $\pm \mathrm{SD}$ or $\mathrm{N}(\%)$. ${ }^{*}$ The population under the RF reference value $(\mathrm{RF}<20 \mathrm{IU})$ was excluded to fit a normal distribution.

Smoking histories were categorized as 'Ever smokers' or 'Never smokers' after RA onset.

with the A/A genotype, while the RF levels in 'never smokers' did not differ between the genotypes.

In fact, this finding of the study, in which we looked at how a specific gene mediates the relationship between smoking and RA severity, may be a false positive or a pattern of linkage disequilibrium due to the multiple comparison issue. Also, the statistical significance of our result is not strong. However, we found certain evidence to support the association due to the robust methods (i.e., data collection, using a powerful statistical tool) and biological plausibility. The NARAC dataset that was used in the present analysis is reliable and stable, having been generated at 12 centers in the USA with well-defined protocols. The data were collected using strict and consistent criteria for inclusion and exclusion, and hand radiographs were used as an entry criterion in the NARAC study to ensure reliability in the diagnosis of $\mathrm{RA}$ and to avoid disease misclassification (Jawaheer et al., 2001). Here, our results were obtained from the PLINK software package, which is a powerful statistical tool for association analyses of individual and family-based data (Purcell et al., 2007).

Furthermore, the rs703618 SNP (STAB2 gene) that was observed in the present study has a biological role that is related to immune function. The STAB2 gene encodes the hyaluronan receptor for endocytosis (HARE), which mediates hyaluronan and chondroitin sulfate clearance from the lymph and blood (Harris et al., 2004). Hyaluronan, which is an important component of synovial fluid and extracellular matrix, is a glycosaminoglycan polymer of repeated units of $\mathrm{N}$-acetylglucosamine and glucuronic acid. Hyaluronan plays essential roles in embryogenesis, angiogenesis, cell proliferation, and wound healing (Stern et al., 2006; Kogan et al.,

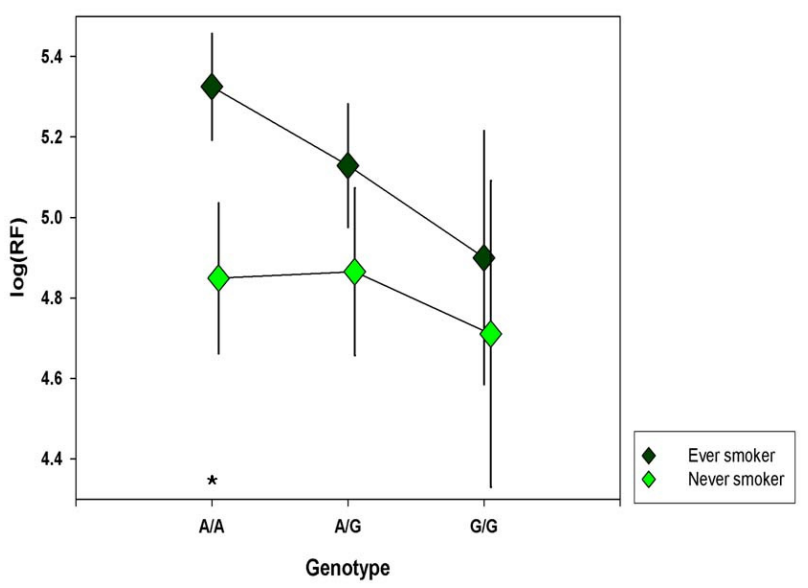

Fig. 4. Mean RF values in relation to the rs703618 genotypes according to smoking history (error bars indicate 95\% $\mathrm{Cl}$ ). The values are adjusted for age and sex. Smoking histories were categorized as 'Ever smokers' or 'Never smokers' after RA onset $\left({ }^{*} p<0.05\right)$.

2007). It has been reported that hyaluronan modulates anti-inflammatory and immunosuppressive functions (Delmage et al., 1986; Bollyky et al., 2007). Bollyky et al. (2007) have suggested that high-molecular-weight hyaluronan enhances the suppressive effects of $\mathrm{CD} 4^{+}$ $\mathrm{CD}^{+} 5^{+}$regulatory $\mathrm{T}$ cells, and this may provide a clue as to the cellular immune response. RA patients show elevated HA levels in their sera and synovial fluid (Engström-Laurent et al., 1985; Goldberg et al., 1991; Nagaya et al., 1999; Majeed et al., 2004). Although the role of the STAB2 gene in the relationship between smoking and RA severity remains questionable, smoking appears to be related to RA severity (or increased RF levels) in terms of the impairment and abnormality of immune functions (Harel-Meir et al., 2007); during these processes, the STAB2 gene appears to reinforce the alteration of immune responses. Thus, stimulation of the STAB2 gene due to smoking may influence immune function and contribute to the severity of RA.

Our study has some major limitations. This study was a case-only design. This is a good approach to screen gene-environment interactions with small standard errors, but it is difficult to generalize results for the general population due to the case selection, and its results may be caused by the linkage disequilibrium between markers and alleles (Ahn et al., 2005; Ahn, 2006). We also restricted the analysis to a comparison of 'ever smokers' and 'never smokers' and did not consider the number of packs of cigarettes that were smoked daily. Some studies have reported that smoking is associated with both the duration and number of packs that is smoked by RA patients (Stolt et al., 2003; Costenbader 
et al., 2006). However, because RA patients are more likely to try to quit smoking, and because we considered that smoking would have a triggering effect on RA (Klareskog et al., 2007), the classification of 'ever smokers' and 'never smokers' is not likely to involve a substantial bias. As mentioned above, the issues about statistical power and multiple comparisons appear to be insufficiently strong enough to confirm our findings. This caveat must be considered when interpreting these findings.

In conclusion, we investigated whether a specific gene acts as a mediator between smoking and the severity of RA by indicating the elevation of RA and found that the STAB2 gene could affect this relationship. Our finding indicates that smoking mediates RA severity by affecting the manifestation of a specific gene and suggests the possibility of gene-environment interactions between smoking and RA severity. Further studies are required to elucidate the biological significance of this finding. Furthermore, it seems likely that an understanding of the gene-environment interactions will be essential for the detection of susceptibility genes for complex diseases.

\section{Acknowledgments}

This study was supported by the grants of the Korean Ministry of Science and Technology (Grant Number M10306030002-03B4803-00210) and BK21 Program.

\section{References}

Ahn, C. (2006). Sample size and power estimation in case-control genetic association studies. Genomics \& Informatics 4, 51-56.

Ahn, C., King, T.M., Lee, K., and Kang, S.H. (2005). DNA pooling as a tool for case-control association studies of complex traits. Genomics \& Informatics 3, 1-7.

Aigner, E., Schmid, I., Osterreicher, C.H., Zwerina, J., Schett, G., Strasser, M., Niksic, F., Hohla, F., Ramsauer, T., Dorn, U., Patsch, W., and Datz, C. (2007). Contribution of anti-cyclic citrullinated peptide antibody and rheumatoid factor to the diagnosis of arthropathy in haemochromatosis. Ann. Rheum. Dis. 66, 1249-1251.

Alamanos, Y., and Drosos, A.A. (2005). Epidemiology of Adult Rheumatoid Arthritis. Autoimmun. Rev. 4, 130-136.

Amos, C.I., Chen, W.V., Lee, A., Li, W., Kern, M., Lundsten, R., Batliwalla, F., Wener, M., Remmers, E., Kastner, D.A., Criswell, L.A., Seldin, M.F., and Gregersen, P.K. (2006). High-density SNP analysis of 642 caucasian families with rheumatoid arthritis identifies two new linkage regions on $11 \mathrm{p} 12$ and 2q33. Gene Immun. 7, 277-286.

Bollyky, P.L., Lord, J.D., Masewicz, S.A., Evanko, S.P., Buckner, J.H., Wight, T.N., and Nepom, G.T. (2007). Cutting edge: high molecular weight hyaluronan promotes the suppressive effects of $\mathrm{CD} 4{ }^{+} \mathrm{CD} 25^{+}$regulatory $\mathrm{t}$ cells. J. Immunol. 179, 744-747.

Cabral, D., Katz, J.N., Weinblatt, M.E., Ting, G., Avorn, J., and Solomon, D.H. (2005). Evelopment and assessment of indicators of rheumatoid arthritis severity: results of a delphi panel. Arthritis Rheum. 53, 61-66.

Costenbader, K.H., Feskanich, D., Mandl, L.A., and Karlson, E.W. (2006). Smoking intensity, duration, and cessation, and the risk of rheumatoid arthritis in women. $A m . J$. Med. 119, 503.e1-9.

de Vries, N., Tijssen, H., van Riel, P.L., and van de Putte, L.B. (2002). Reshaping the shared epitope hypothesis: hla-associated risk for rheumatoid arthritis is encoded by amino acid substitutions at positions $67-74$ of the HLA-DRB1 molecule. Arthritis Rheum. 46, 921-928.

Delmage, J.M., Powars, D.R., Jaynes, P.K., and Allerton, S.E. (1986). The selective suppression of immunogenicity by hyaluronic acid. Ann. Clin. Lab. Sci. 16, 303-310.

Engström-Laurent, A., and Hällgren, R. (1985). Circulating hyaluronate in rheumatoid arthritis: relationship to inflammatory activity and the effect of corticosteroid therapy. Ann. Rheum. Dis. 44, 83-88.

Goldberg, R.L., Huff, J.P., Lenz, M.E., Glickman, P., Katz, R., and Thonar, E.J. (1991). Elevated plasma levels of hyaluronate in patients with osteoarthritis and rheumatoid arthritis. Arthritis Rheum. 34, 799-807.

Gregersen, P.K., Silver, J., and Winchester, R.J. (1987). The shared epitope hypothesis. an approach to understanding the molecular genetics of susceptibility to rheumatoid arthritis. Arthritis Rheum. 30, 1205-1213.

Harel-Meir, M., Sherer, Y., and Shoenfeld, Y. (2007). Tobacco smoking and autoimmune rheumatic diseases. Nat. Clin. Pract. Rheumatol. 3, 707-715.

Harris, E.N., Weigel, J.A., and Weigel, P.H. (2004). Endocytic function, glycosaminoglycan specificity, and antibody sensitivity of the recombinant human $190-\mathrm{kDa}$ hyaluronan receptor for endocytosis (HARE). J. Biol. Chem. 279, 36201-36209.

Harrison, B.J. (2002). Influence of cigarette smoking on disease outcome in rheumatoid arthritis. Curr. Opin. Rheumatol. 14, 93-97.

Jawaheer, D., Seldin, M.F., Amos, C.I., Chen, W.V., Shigeta, R., Monteiro, J., Kern, M., Criswell, L.A., Albani, S., Nelson, J.L., Clegg, D.O., Pope, R., Schroeder, H.W. Jr., Bridges, S.L. Jr., Pisetsky, D.S., Ward, R., Kastner, D.L., Wilder, R.L., Pincus, T., Callahan, L.F., Flemming, D., Wener, M.H., and Gregersen, P.K. (2001). A genomewide screen in multiplex rheumatoid arthritis families suggests genetic overlap with other autoimmune diseases. $A m$. J. Hum. Genet. 68, 927-936.

Klareskog, L., Padyukov, L., and Alfredsson, L. (2007). Smoking as a trigger for inflammatory rheumatic diseases. Curr. Opin. Rheumatol. 19, 49-54.

Klareskog, L., Padyukov, L., Rönnelid, J., and Alfredsson, L. (2006). Genes, environment and immunity in the development of rheumatoid arthritis. Curr. Opin. Immunol. 18, 650-655.

Kogan, G., Soltés, L., Stern, R., and Gemeiner, P. (2007). Hyaluronic acid: a natural biopolymer with a broad range 
of biomedical and industrial applications. Biotechnol. Lett. $29,17-25$.

Lee, D.M., and Weinblatt, M.E. (2001). Rheumatoid arthritis. Lancet. 358, 903-911.

Majeed, M., McQueen, F., Yeoman, S., and McLean, L. (2004). Relationship between serum hyaluronic acid level and disease activity in early rheumatoid arthritis. Ann. Rheum. Dis. 63, 1166-1168.

Masdottir, B., Jónsson, T., Manfredsdottir, V., Víkingsson, A., Brekkan, A., and Valdimarsson, H. (2000). Smoking, rheumatoid factor isotypes and severity of rheumatoid arthritis. Rheumatology 39, 1202-1205.

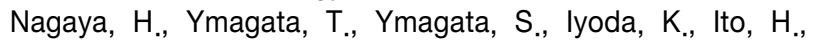

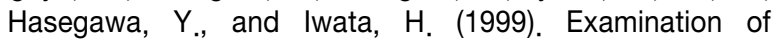
synovial fluid and serum hyaluronidase activity as a joint marker in rheumatoid arthritis and osteoarthritis patients (by zymography). Ann. Rheum. Dis. 58, 186-188.

NARAC website. http://www naracdata.org.

Padyukov, L., Silva, C., Stolt, P., Alfredsson, L., and Klareskog, L. (2004). A gene-environment interaction between smoking and shared epitope genes in HLA-DR provides a high risk of seropositive rheumatoid arthritis. Arthritis Rheum. 50, 3085-3092.

PLINK software. http://pngu.mgh.harvard.edu/ purcell/plink/. Purcell, S., Neale, B., Todd-Brown, K., Thomas, L., Ferreira, M.A., Bender, D., Maller, J., Sklar, P., de Bakker, P.I., Daly, M.J., and Sham, P.C. (2007). PLINK: a tool set for whole-genome association and population-based linkage analyses. Am. J. Hum. Genet. 81, 559-575.

Saag, K.G., Cerhan, J.R., Kolluri, S., Ohashi, K., Hunninghake, G.W., and Schwartz, D.A. (1997). Cigarette smo- king and rheumatoid arthritis severity. Ann. Rheum. Dis. 56, 463-469.

SAS institute Inc. (1999). SAS OnlineDoc, Version 8. Cary, NC: SAS Institute Inc.

Silman, A.J., Newman, J., and MacGregor, A.J. (1996). Cigarette smoking increases the risk of rheumatoid arthritis. Results from a nationwide study of disease- discordant twins. Arthritis Rheum. 39, 732-735.

Stern, R., Asari, A.A., and Sugahara, K.N. (2006). Hyaluronan fragments: an information-rich system. Eur. J. Cell. Biol. 85, 699-715.

Stolt, P., Bengtsson, C., Nordmark, B., Lindblad, S., Lundberg, I., Klareskog , L., Alfredsson L., and EIRA study group. (2003). Quantification of the influence of cigarette smoking on rheumatoid arthritis: results from a population based case-control study, using incident cases. Ann. Rheum. Dis, 62, 835-841.

Taylor, K.E., Chen, W., Amos, C.I., and Criswell, L.A. (2007). Genome-wide single-nucleotide polymorphism linkage analyses of quantitative rheumatoid arthritis phenotypes in caucasian NARAC families. BMC Proc. 1, S105-S109.

Turesson, C., and Matteson, E.L. (2006). Genetics of rheumatoid arthritis. Mayo Clin. Proc. 81, 94-101.

Westwood, O.M., Nelson, P.N., and Hay, F.C. (2006). Rheumatoid factors: what's new? Rheumatology 45, 379-385.

Wolfe, F. (2000). The effect of smoking on clinical, laboratory, and radiographic status in rheumatoid arthritis. $J$. Rheumatol. 27, 630-637. 